\title{
Ecological half-life of I-131 in milk after dry and wet radionuclide deposition due to the Chernobyl accident
}

\author{
I. Zvonova, A. Bratilova, T. Jesko, S. Sarycheva and M. Fomintceva \\ Research Institute of Radiation Hygiene, ul. Mira, 8, 197101 St. Petersburg, Russia
}

\begin{abstract}
Numerous measurements of ${ }^{131}$ I concentration in milk following the Chernobyl accident have shown a wide range of clarification half-life values. By results of spectrometric measurements of the milk, performed in 1986 in Tula region (Russia), a connection between a ${ }^{131}$ I decreasing half-life in milk and a level of radioactive contamination in a locality and a level of precipitation during passage of a radioactive cloud is analysed. Values of the ${ }^{131} \mathrm{I}$ half-life in milk increase from $3.0 \mathrm{~d}$ at the smallest area contamination by ${ }^{137} \mathrm{Cs}$ to $5.5-6.0 \mathrm{~d}$ at the contamination above the $200 \mathrm{kBq} / \mathrm{m}^{2}$. The half-life of ${ }^{131} \mathrm{I}$ removal from milk depends on the precipitation level at the time of radioactive fallouts in places of milk sampling. $T_{\text {ef }}$ increases from 2.8-3.5 d (dry deposition) to the value 5.5-6.0 with precipitation increasing up to 6-9 $\mathrm{mm}$. The half-life value does not change with further precipitation increase. This finding should be taken into account in thyroid dose estimations for inhabitants of contaminated areas.
\end{abstract}

\section{INTRODUCTION}

Radioactive fallout caused by the Chernobyl accident has contaminated 19 regions of Russian Federation. At the first month following the accident ${ }^{131} \mathrm{I}$ had a most radiation impact on the environment and population of contaminated areas. ${ }^{131} \mathrm{I}$ was coming into human body with contaminated air and food, it got accumulated in the thyroid and, as a result, the highest absorbed doses were formed in this organ. ${ }^{131}$ I intake with contaminated milk provided up to $90-95 \%$ of the absorbed dose in thyroids of people in areas, where cattle was at pasture forage. A method of thyroid dose reconstruction was developed and approved by the Russian Ministry of Public Health for dose estimation in the thyroid due to ${ }^{131} \mathrm{I}$ for the population in settlements where ${ }^{137} \mathrm{Cs}$ surface contamination was equal or higher to $37 \mathrm{kBq} / \mathrm{m}^{2}$ $\left(1 \mathrm{Ci} / \mathrm{km}^{2}\right)[1]$.

The method used an effective half-life value of ${ }^{131} \mathrm{I}$ decreasing in milk $\left(\mathrm{T}_{\mathrm{ef}}\right)$ equal to $\mathrm{T}_{\mathrm{ef}}=4.2 \mathrm{~d}$. This value was received from the analysis of ${ }^{131}$ I measurements in milk in May-June 1986 in the four most contaminated regions of Russia [2]. Averaged over each day of measurements ratios of ${ }^{131}$ I concentration in milk to soil contamination with ${ }^{137} \mathrm{Cs}$ in the place of sampling reduced in four independent sets of milk measurements with half-life from 3.9 to $4.2 \mathrm{~d}$. The same data taken for separate localities gave values $\mathrm{T}_{\mathrm{ef}}$ within limits of 2.5-6.5 days. A large variability of ${ }^{131} \mathrm{I}$ effective half-life in milk were found in different studies after the Chernobyl accident [3]. Half-life of ${ }^{131}$ I removal out of milk defines the dynamics of radioiodine intake into human body and directly changes the thyroid dose estimations. Depending on the used numerical value of $\mathrm{T}_{\mathrm{ef}}$, dose estimation can be changed by two times, that could significantly influence on the epidemiological studies of thyroid morbidity after the Chernobyl accident especially for case-control studies.

Regularities of ${ }^{131}$ I half-life in milk depending on soil contamination with ${ }^{137} \mathrm{Cs}$ and precipitations during fallout time are considered in the paper.

\section{MATERIALS AND METHODS}

The main part of the experimental data was received in Tula region of Russia which is located about $200 \mathrm{~km}$ south of Moscow, and about 550-750 km north-east of Chernobyl NPP. This area was 
significantly contaminated with radioactive fallout on April 29-30, $1986 .{ }^{137} \mathrm{Cs}$ soil contamination density varied from 0 to $0.5 \mathrm{Mbq} / \mathrm{m}^{2}$.

Spectrometric measurements of ${ }^{131} \mathrm{I}$ content in milk samples in Tula region were carried out from May 14 till June 12, 1986. A one channel spectrometer on the base of the crystal of $\mathrm{NaI}(\mathrm{Tl})$ $\varnothing 40 \times 40 \mathrm{~mm}$ was used for this purpose. The detector was put inside the cylindrical leaden collimator in vertical position. A thin glass with $100 \mathrm{ml}$ of milk was placed on the detector's face. Measurements were done in the energy interval of ${ }^{131} \mathrm{I}$ gamma-radiation: $150-450 \mathrm{keV}$. The minimally detected activity (MDA) of ${ }^{131} \mathrm{I}$ in the sample with 100 seconds of measurement and $95 \%$ of confidence probability was equal to $0.2 \mathrm{kBq} / \mathrm{l}$. Totally there were performed 1744 measurements of milk samples. A number of measurements with the sample activity lower than the MDA increased significantly in June. So in this study only 867 measurements made from 14 to 28 of May 1986 were used. Effective half-life of ${ }^{131}$ I concentration decrease in milk was defined for each farm where milk was sampled no less than on three different dates.

It is necessary to note that the information on the ${ }^{131} \mathrm{I}$ in milk samples initially contained some inaccuracy. The place of sampling was recorded in working notebooks as the name of a collective farm without a settlement name. A collective farm could include from 3 to 12 settlements with different level of radioactive contamination of soil. Dairy cattle usually passed from one pasture to another within the limits of a collective farm's lands. So a milk sample was compared to a mean level of ${ }^{137} \mathrm{Cs}$ soil contamination in a collective farm calculated as an arithmetic mean among contaminations of included settlements. Large differences in soil contamination of some collective farm sites could result in significant scattering of ${ }^{131}$ I concentration in milk. Taking these uncertainties into account, the results of half-life determinations with standard deviation above critical value 0.2 were not taken into consideration. A locality was not included the analysis if at least one of the measurements was below the MDA.

\section{RESULTS AND DISCUSSION}

Half-life of ${ }^{131} \mathrm{I}$ removal in milk, $\mathrm{T}_{\text {ef }}$, was defined for 63 localities in Tula region. Its values with SD are shown in Fig. 1 in dependence on ${ }^{137} \mathrm{Cs}$ soil contamination of the place of sampling.

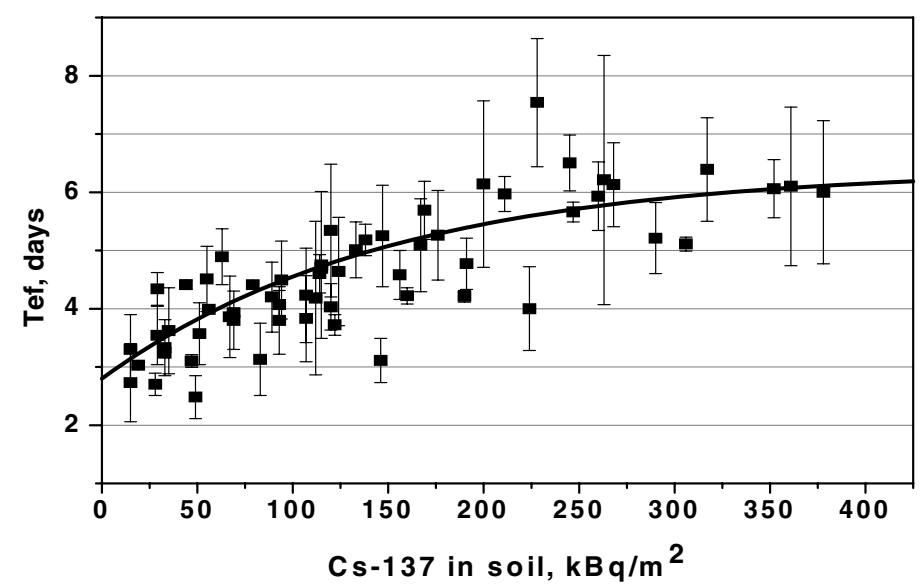

Figure 1. Effective half-life of ${ }^{131} \mathrm{I}$ decreasing in milk depending on ${ }^{137} \mathrm{Cs}$ soil contamination density.

It is seen that the ${ }^{131}$ I removal velocity became slower with the increasing of ${ }^{137} \mathrm{Cs}$ contamination density in soil. Estimations of $\mathrm{T}_{\text {ef }}$ increase from $2.5-3.5 \mathrm{~d}$ in areas with low ${ }^{137} \mathrm{Cs}$ soil contamination 
less than $30 \mathrm{kBq} / \mathrm{m}^{2}$ to the approximately constant value $5.9 \pm 0.5 \mathrm{~d}$ in areas where ${ }^{137} \mathrm{Cs}$ density in soil was higher $200 \mathrm{kBq} / \mathrm{m}^{2}$.

Analytical approximation of the experimental data could be made in different ways, for example a rather good description gives an exponential function:

$$
\mathrm{T}_{\mathrm{ef}}=6,6-3,8 \cdot \exp \left(-\sigma_{137} / 200\right) \text {, }
$$

where $\sigma_{137}$ is ${ }^{137} \mathrm{Cs}$ soil contamination density, $\mathrm{kBq} / \mathrm{m}^{2}$. However we choose a piecewise continuous function with linear increase in the range of $\sigma_{137}$ from 0 to $220 \mathrm{kBq} / \mathrm{m}^{2}$ and a constant value at higher soil contamination levels:

$$
\begin{aligned}
& \mathrm{T}_{\mathrm{ef}}=2,8+0,014 \cdot \sigma_{137}, \mathrm{~d}, \quad \text { if } 0<\sigma_{137}<220 \mathrm{kBq} / \mathrm{m}^{2} \\
& \mathrm{~T}_{\mathrm{ef}}=5,9 \mathrm{~d}, \quad \text { if } \sigma_{137} \geq 220 \mathrm{kBq} / \mathrm{m}^{2}
\end{aligned}
$$

All measurements of ${ }^{131} \mathrm{I}$ concentration in milk were re-calculated on the date of beginning mass measurements of milk samples - 14.05.1986 using values of $\mathrm{T}_{\mathrm{ef}}$ according to Eq. (1). Fig. 2 demonstrates the comparison of the reconstruction results of ${ }^{131}$ I concentration in milk with the measurements on 14 May 1986 depending on ${ }^{137}$ Cs soil contamination density. Points at the Fig. 2 mark mean values with SD of measured ${ }^{131}$ I concentrations in milk averaged over narrow range of ${ }^{137} \mathrm{Cs}$ contamination in places of sampling. The solid line designates approximation of all measurements of milk reconstructed on 14.05.1986. This function is described by the following equation:

$$
\mathrm{T}_{\mathrm{ef}}=\left(2,1+0,024 \cdot \sigma_{137}\right) \cdot\left(1-\exp \left(-\sigma_{137} / 20\right)\right)
$$

Estimated function agrees with the experimental data rather well. This confirms a reliability of the derived dependence of ${ }^{131} \mathrm{I}$ removal in milk half-life on ${ }^{137} \mathrm{Cs}$ surface density in a locality of sampling.

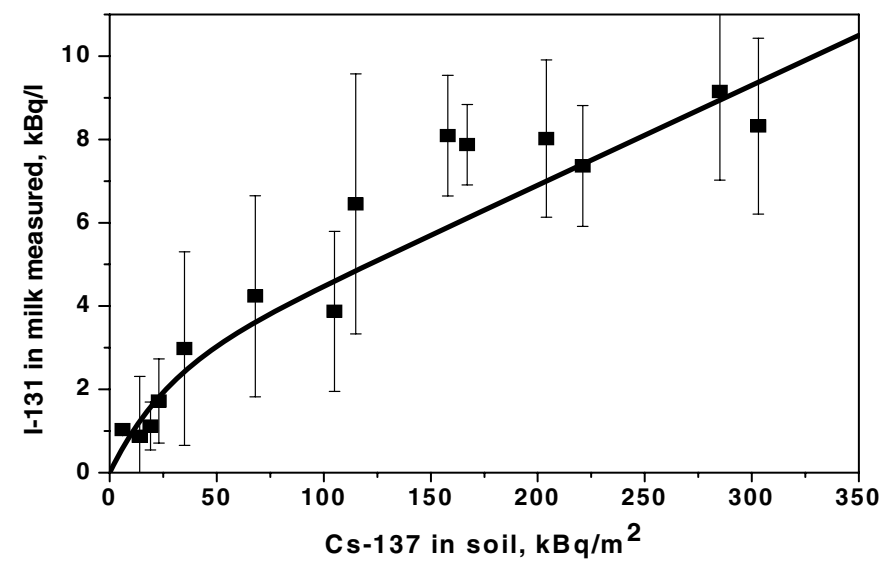

Figure 2. Dependence of the measured ${ }^{131} \mathrm{I}$ concentration in milk samples (points with SD bars) and an approximation of all reconstructed measurements on the same date (solid line) on ${ }^{137} \mathrm{Cs}$ contamination in places of sampling.

Differences in half-life velocity ${ }^{131}$ I removal out of milk in low and high contaminated areas can be explained by different types of fallouts: low contamination was formed mainly due to dry deposition, high contamination - because of wet deposition. After the dry deposition ${ }^{131}$ I intake into cow's body with gramma grass slowed down due to the radioactive decay, weathering factors, the growth of vegetative mass. The velocity of ${ }^{131}$ I intake into cow's body reflects on the dynamics of ${ }^{131}$ I removal from milk. After wet deposition the removal velocity diminished due to root intake of ${ }^{131} \mathrm{I}$ from the soil to grass. If the decrease of the velocity of milk clearance from ${ }^{131} \mathrm{I}$ aroused only from the process of ${ }^{131} \mathrm{I}$ root 
intake a constant of this process can be estimated as $0 . \mathrm{d}^{-1}$ which corresponds to the half-life of root intake $3.4 \mathrm{~d}$.

Some data on correlation of ${ }^{131}$ I removal half-life with a level of atmospheric precipitation at the time of radioactive cloud passing over places of milk sampling are shown at the Fig. 3. Data of radiochemical analysis and spectrometric measurements of milk in separate areas of neighborhood regions where precipitations measurements were available were used for the construction of the graph (four points) in addition to the data from Tula region. Half-life of ${ }^{131} \mathrm{I}$ removal from milk increased from 3.0-3.5 d at dry deposition to 5.5-6.0 d when level of precipitations reached or exceed 6-9 $\mathrm{mm}$ of rains.

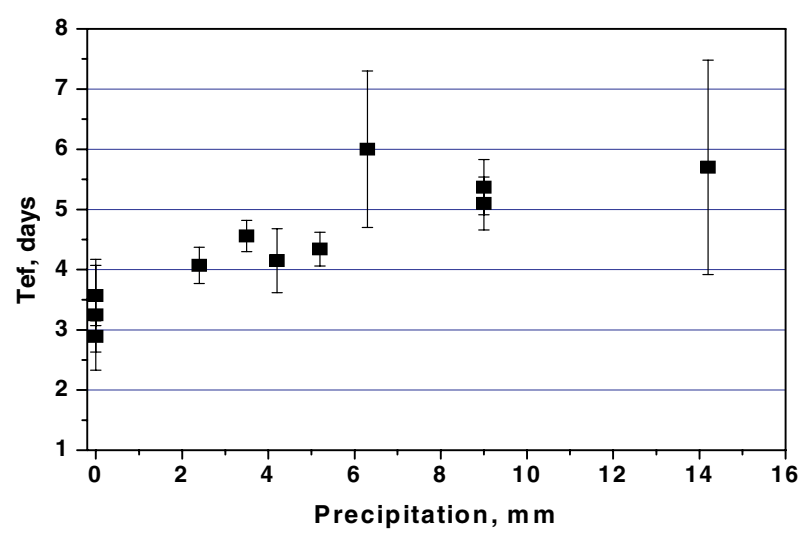

Figure 3. Correlation of ${ }^{131}$ I removal from milk half-life, $T_{\text {ef }}$, with a level of atmospheric precipitation at the time of radioactive fallouts in places of milk sampling.

Taking into account this finding a correction of thyroid dose estimations for inhabitants of contaminated areas after the Chernobyl accident is required. The variable period depending on quantity of precipitation or on contamination level should be used in the thyroid dose reconstruction by ecological models, or by empirical regularities.

\section{CONCLUSIONS}

1. Analysis of the ${ }^{131} \mathrm{I}$ measurements in milk after the Chernobyl accident showed that half-life of ${ }^{131}$ I removal from milk correlates with ${ }^{137} \mathrm{Cs}$ surface density in soil increasing from $2.8-3.5 \mathrm{~d}$ at contamination level less than $10 \mathrm{kBq} / \mathrm{m}^{2}$ to the value $5.9 \pm 0.5 \mathrm{~d}$ at ${ }^{137} \mathrm{Cs}$ density above $200 \mathrm{kBq} / \mathrm{m}^{2}$.

2. The half-life of ${ }^{131} \mathrm{I}$ removal from milk depends on the precipitation level at the time of radioactive fallouts in places of milk sampling. $\mathrm{T}_{\text {ef }}$ increases from 2.8-3.5 d (dry deposition) to the value 5.5-6.0 with precipitation increasing up to $6-9 \mathrm{~mm}$. The half-life value does not change with further precipitation increase.

\section{References}

[1] Russian Ministry of Public Health. MU 2.6.1.1000-00 (2000). Moscow: (2001) 61 p.

[2] I.A. Zvonova, M.I. Balonov, A.A. Bratilova. Radiatin Protection Dosimetry 79, 175-178 (1998).

[3] Kirchner G. Health Physics 66, 653-664 (1994). 